\title{
Understanding the Factors Affecting the Adoption of Green Computing in the Gulf Universities
}

\author{
ARWA IBRAHIM AHMED \\ Department of Information System \\ Princess Nourah Bint Abdulrahman University (PNU) \\ Riyadh, KSA
}

\begin{abstract}
Many universities worldwide have adopted, or are intend to adopt green computing in their campuses to improve environmental sustainability and efficient-energy consumption. However, the factors affect the adoption of green computing are still not understood. The aim of this study is to investigate the key success factors affecting the adoption of green computing in developing countries' universities, specifically in Gulf States universities. This study draws mainly on the TOE model suggested by Tornatzky and Fleischer [1] to understand the key areas for the success factors of green computing adoption. Data was collected based on survey research design to 118 Gulf universities. The findings revealed that the top five success factors affect the adoption of green computing in gulf universities are: awareness, relative advantage, top management support, adequate resources and government policy. Moreover, among the proposed three contexts the most important one is organizational, followed by environmental, and finally technology factors. This study contributes to the theory by providing taxonomy of the factors affecting the adoption of green computing. For practitioners, this study will assist the decision makers in gulf countries to benefit from the findings of this study to make well informed decisions by focusing on the key factor that have a greater impact on adopting green computing.
\end{abstract}

Keywords-Success factors; green computing; TOE model and universities

\section{INTRODUCTION}

Green computing has recently become an imperative aspect in the information technology industry. The rising level of energy consumption, global warming and e-waste have led to pay much attention in green computing by governments and businesses worldwide as kind of moral and environmental commitment for sustainable improvement [2]. Green computing is the process of implementing policies and procedures that support both individual and business computing needs in ecofriendly and sustainable way that enhance the efficiency of computing resources and minimize the energy consumption impact on the environment [3]. Some of the benefits of adopting green computing include ensuring an environmental and economic sustainability, utilizing the recourses in an environmental friendly manner, maintaining the computing performance while minimizing enormous and wasteful consumption of energy and carbon footprint, cutting down costs and improving business and social image [2], [4].

Over the past years, energy consumption concerns have been considered as one of key challenges for IT industry globally. Statistics indicated that the IT industry's $\mathrm{CO}_{2}$ emission represents approximately $2 \%$ of global $\mathrm{CO}_{2}$ emissions [5], [6]. The concerns rise over huge amounts of dollars spent annually on wasteful and unnecessary computing, where experts mentioned that the cost of wasted energy in computing industry is estimated about $\$ 212.5$ billion per year [7]. As a result of these concerns, many leading companies attempted to adopt green computing in their operations depending on renewable energy in order to improve computing performance, reduce energy consumption and develop IT operations in a sustainable manner. For example, Yahoo, Microsoft and Google sought to build their data centers in the cities that have renewable energy resources such as hydroelectric, solar and wind power to take advantage of these power, reduce cost and maintain environmental sustainability [8].

Issues related to the green computing have been widely discussed in existing literature. However, much of the green computing research to date have limited to prescriptive and rhetorical studies only. For example, Bisoyi and Das [9] highlight the factors that motivate businesses to implement ewaste management as a kind of green computing practice. They recommended that the lack of awareness, legislative and regulatory aspects, complexity of the materials used, appearance of hazardous substances, availability of appropriate technologies, and the risk in supply chain are among the key issues related to implementation of e-waste management. Similarly, Singh [10] discussed the main issues facing green computing implementation which include infrastructure for environmental sustainability, power management techniques, virtualization, energy efficient coding and recycling. In another study, Borah, et al. [11] investigates the enormous wastage of energy in IT industry and how green computing implementation reduces wasteful consumption of energy in small, medium and large enterprises. A number of studies [11][14] addressed the requirements and strategies needed for green computing in a cloud computing environment. They found that the virtualization, terminal servers, power management, power aware hybrid deployment, task consolidation and improve awareness are among the important techniques required to reduce power consumption, minimize toxic gas emissions, and make cloud computing more environmental friendly and more efficient energy usage. Ahmad, et al. [15] emphasized that the successful adoption and implementation of green computing is mainly rely on understanding the success factors of green computing. However, these factors are still poorly understood in the existing literature [5]. Therefore, this study aims to understand 
the factors affecting the adoption of green computing in universities, specifically in the context of gulf universities.

Recently, gulf countries have identified renewable energy as a top priority in their agenda and have adopted, or are in the process of adopting green initiatives in all sectors, and the green computing in education sector is certainly no exception. Gulf governments are heavily investing in green projects in order to ensure an environmental and economic sustainability. For example, in 2017 Saudi Arabia spent on renewable energy projects more than $\$ 50$ billion with the purpose of cutting down oil use, as well as transforming towards green power in meeting growing energy demand [16]. However, the adoption of green computing is new trend in gulf countries which used to domestic oil use as a main source of energy. Moreover, green computing adoption involves many obstacles and complex processes [10], [17]. Yet, there is lack to empirical evidence to understand the success factors required to manage the adoption green computing successfully [5]. Therefore, this paper is important particularly in the context of gulf countries as developing countries, where most of the recent research of green computing in developing nations indicated that they are suffering from difficulty of managing the adoption of green computing, and struggling with a lack of resources and experiences to handle this new trend of technology. Moreover, the significance of this study lies in providing guidelines for decision makers in gulf universities to optimize their resources and efforts, how they can improve their investments in this new approach, and avoid the potential risks and challenges facing the adoption of green computing.

\section{GREEN COMPUTING}

Many organizations and individuals around the world have taken advantage of the digital revolution and are already utilizing the IT systems and its features in their daily work. While the use of IT systems are growing rapidly and the computing makes life easier and work faster, it increases significantly power consumption, which in turn amplifies the amount of carbon and hazardous gas emissions [10]. As a result, Green computing is gaining great importance in practical and academic fields. It became utmost priority of the modern world today to save energy consumption, reduce carbon emissions, cut down operational expenses and sustain a green environment [2], [15].

Green computing can be defined as the use of computers the efficient use of computers and its related technology in an ecofriendly manner with the purpose of reducing energy consumption, hazardous gas emissions and sustaining an environment [10]. Murugesan [18] has even broader concept of green computing, who elucidated that the green computing is "the study and practice of designing, manufacturing, using and disposing of computers, servers, and associated subsystems, such as monitors, printers, storage devices, and networking and communication systems, efficiently and effectively with minimal or no impact on the environment" [18 pp. 25-26]. The origin of green computing traced back to 1992 when the U.S. Environmental Protection Agency (EPA) launched Energy Star program with the aim of minimizing energy consumption of computing products [2], [10], [15]. Simultaneously, the Swedish organization TCO Development for sustainable IT introduced the TCO Certification initiative in order to reduce hazardous emissions from computer materials and support environmentally sustainable computing implementation [17]. These initiatives resulted in wide adoption of the sleep mode for computer monitors as a first step towards green computing. Since then, green computing concept has widely extended to cover all aspects of IT products including CPUs, networks, servers, processors, networks and monitors [2], [15]. During the past two decades, green computing has been developing to include e-waste by designing ecofriendly or green-oriented software, and manufacturing hardware from disposable materials in order to reduce the harmful impacts of computing.

Murugesan [18] identified four key domains of green computing to address the environmental impacts of IT, namely: green use, green disposal, green design and green manufacturing of IT systems (as shown in Fig. 1). According to Murugesan [18], these domains are not only involve efficient energy and carbon free computing, rather they also include hazardous materials used in manufacturing of IT products that have harmful impacts on the environment. There are several methods to implement green computing which can be classified into three main categories, are [10], [14]: 1) improve the efficiency of energy consumption by minimizing the carbon emissions; 2) decrease e-waste as much as possible; and 3) transform the lifestyle towards more environmental friendly and sustainability. With the tremendous development of technology, day to day the adoption and implementation of green computing is gaining a considerable attention globally. The implementation areas of green computing are extending to involve everything that is green. This includes, for example but not limited to, data centers, infrastructure, technology used, virtualization, cloud computing, Internet of Things (IoT), intelligent computing, big data, renewable energy, green buildings, green IT policies, and any green initiative or ideas contribute to reduce energy consumption and carbon emissions and sustain environment [9], [14], [15], [19].

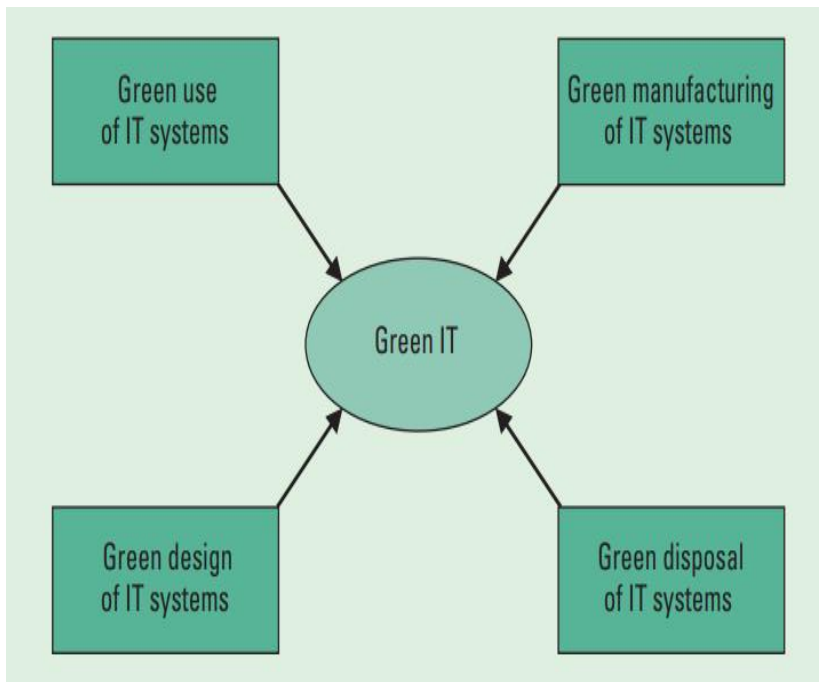

Fig. 1. Green computing domains suggested by Murugesan [18].

Although numerous studies have addressed green computing and its influence on efficient energy consumption and reduce the harmful impact of technology on environment, 
the computing worldwide remain has a huge negative impact on environment [19]. Yet, most of green computing projects in developing countries have not been fully exploited to achieve the desired environmental sustainability, and the goals of its adoption are still unrealized [10]. This is due to the fact that the successful adoption and implementation of green computing does not only requires using, designing and manufacturing IT system, but also it requires mainly considering many critical factors such as environmental and organizational elements which are imperative for successful adoption of green computing [5], [17]. However, these factors for green computing adoption have been ignored in the existing literature and still unexplored research area [5]. Therefore, this study fills the gap in the literature by investigating the factors affecting the adoption of green computing using the case of gulf universities.

The use of IT systems is very common in almost all universities worldwide. It became an imperative part of daily practices of administrators, academics and students to utilize of computers, e-learning platforms, monitors, software, printers, projectors and social media networks for edutainment. Therefore, green computing initiatives and theirs adoption are gaining a particular importance in universities, and they are already shaping the actual practices in all aspects of learning processes. The universities contribute significantly to enhance green computing practices through raising awareness among academics, students and society as a whole on how to efficient use of computing resources in an ecofriendly manner and reduce energy consumption and carbon emissions [15]. Moreover, universities consider as a lead by example of green computing applications, as they practice the green applications to support their computing activities and for scientific research purposes [20].

A number of universities around the world have adopted green computing projects to sustaining a green environment. For example, the University of Utah in the United States, launched e-waste management initiative to reduce e-waste and maintain a sustainability by adopting green policy and implementing a set of measures in its campus such as identifying the dates on which e-waste will be collected. In addition, the University of Copenhagen in Denmark built an efficient energy services center for students in 2009. This building is supported by a renewable energy such as solar panels and it is totally carbon free. The University of Copenhagen also institutionalized the green computing concept by adopting well-planed strategy to improve green habits and practices among staff and students. This strategy resulted in minimizing the energy consumption and the amount of carbon emissions by $2.5 \%$ yearly [15]. The Australian National University has sought to adopt cloud computing as kind of green computing applications to support environmentally sustainable computing in its campus. From this approach, the university transformed completely towards e-learning as green way of reducing energy consumption and toxic gas emissions [21]. However, many universities globally, particularly in developing countries, are suffering on how manage green computing projects, and they lack to the experience in handling the issues facing this new trend in their environment and the factors required to avoid the failure [15], [22].
Having reviewed green computing literature, only few researches provided some insight about the green computing state in higher education institutions. For example, Ahmad, et al. [15] examined the awareness of green computing among students in Malaysian universities. While, Paul and Ghose [20] addressed the issues related to green computing practices in Indian universities. Nevertheless, the investigation of the factors affecting the adoption of green computing in universities is still extremely unexplored research area.

\section{RESEARCH MODEL}

The proposed model of this study is theoretically draws on the Technology-Organization-Environment (TOE) framework suggested by Tornatzky and Fleischer [1]. The TOE comprises three contexts that affect the adoption of any IT innovation which are: technology, organizational and environmental elements. The technology context involves the available IT systems and its related technologies such as software, hardware and networks. Organizational context refers to the characteristics of organizations such as organizational culture, organizational structures, strategies and size. The environmental context is the field in which an organization operates and conducts its business. This includes competitors, partners, legislations and government policies [1].

The TOE model offers a solid theoretical base to gain indepth insight about the adoption of IT innovations and initiatives, and it has been widely used in different IT areas by many scholars to understand the success factors that affect the adoption of new IT initiatives, such as e-commerce [23], cloud computing [24], [25], e-Learning [26], Enterprise Resource Planning (ERP) systems [27], and E-Medical Record (EMR) systems [28]. However, there is lack of studies that employed the TOE to examine the success factors affecting the adoption of green computing in context of universities.

The TOE model is useful to help in achieving the objective of this research, as it contains an essential context for green computing adoption such as organizational, and environmental contexts. Numerous studies indicated that the adoption of green computing is not merely about the technology aspects, rather it is contingent upon understand other organizational and environmental factors which are imperative and should be considered for the success of green computing initiatives [5], [17], [22]. Moreover, this model helps to investigate the green computing adoption at organization level instead of individual level, and thus it provides further insight on how organization influences and is influenced by the contexts of new IT innovations adoption [29]. Therefore, the TOE assists in exploring the key areas for the success factors of green computing adoption.

Based on TOE framework and the results of green computing and related IT literature, this study suggests three dimensional model (as shown in Fig. 2), which includes the factors of technology, organizational and environmental to understand the adoption of green computing in universities. This study posits that these three contexts will positively affect the universities' decisions to adopt green computing. 


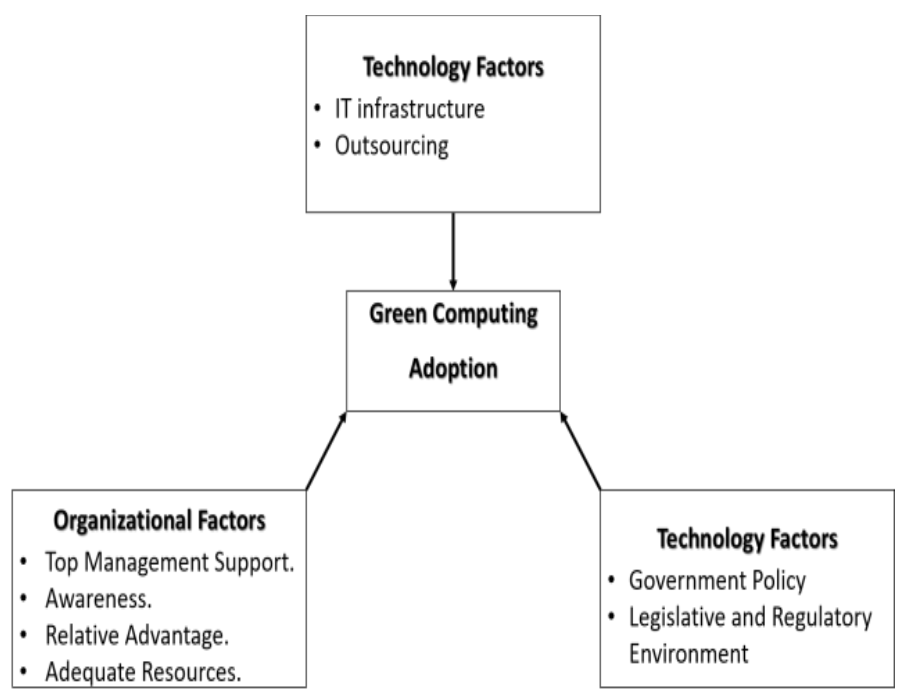

Fig. 2. Research model.

\section{A. Technology Factors}

The technology factors involve the internal and external technologies that influence on the adoption of new IT initiatives in particular organization. It also embraces the actual software, hardware, networks and how they are adapted in effective manner to achieve the best practices of green computing [3]. In this study, technology factors comprise IT infrastructure and outsourcing. The fact of green computing adoption requires mainly having an adequate and flexible hardware and software features that are designed and manufactured to reduce energy consumption and carbon emissions, decrease e-waste, and enable to conduct an adaptive maintenance to maintain environmental sustainability [8], [18]. This in turn ensures the green usage of IT systems. Therefore, the IT infrastructure is considered as one of an imperative factor in green computing adoption.

Many studies have also indicated that outsourcing will significantly motivate green computing adoption decision [29], [30]. The outsourcing strategy assists to assure greenness environment in the organizations and increase energy efficiency improvements at low cost. Numerous scholars have emphasized the outsourcing such as fog computing, grid computing and cloud computing are the most effective approaches towards adoption of green computing as they create an ecofriendly infrastructure with e-waste free organization [12], [13], [17]. It contributes greatly to obtain green environmental benefits of virtualization and thus enhance the performance of computing while minimizing energy consumption of data-centers (3\#; 4\#; 10\#; 11\#). Consequently, the outsourcing is another key technological factor for green computing adoption.

\section{B. Organizational Factors}

Organizational factors are an internal mechanisms, processes and strategies that affect the organization's intention to adopt new IT innovations. In this study, the organizational context embraces different factors, are: top management support, awareness, relative advantage and adequate resources. Top management support has been considered by several scholars as an imperative factor for adoption any new IT initiative [28], [29]. Top management support is perceived as the commitment and support of executives and they understand and realized the benefits and functions of green computing [31]. As a matter of fact, the adoption of green computing involves many challenges, risks, costs, and it requires allocate resources and reengineer some process and infrastructure. Consequently, it is essential to have a powerful and supportive management to overcome obstacles and address issues facing the adoption of green computing. From this viewpoint, top management support plays a critical role before and after the adoption decision of green computing in universities.

Awareness refers to the knowledge or perceptions of students and staff about green computing practices and its capabilities in promoting environmental sustainability. Many studies indicated that the awareness is an important foundation to ensure the success of green computing projects [2], [13], [14]. According to Ahmad, et al. [15], raising awareness among students and other end users is the first step toward green computing adoption in universities. Relative advantage can be defined as "the degree to which an innovation is perceived as being better than the idea it supersedes" [32]. It also refers to verifying whether green computing project can cut down operating costs and rise the relative benefits for universities and environment. A number of studies affirmed that relative advantage greatly affect organizations and motivate them to adopt new IT initiatives [31], [33]. In addition, the adoption of green computing is often a large project, particularly in universities, which in turn requires having an adequate budget and human resource, sufficient schedule, and effective involvement by top management. Therefore, availability of adequate resources is among essential aspects to the success of IT initiatives adoption [31], [34].

\section{Environmental Factors}

Environmental factors represent an external pressure in the current operating environment of universities that affect the decision adoption of green computing. In this study, environmental factors consist of two factors, are legislative and regulatory environment, and government policy. (2\#) affirmed that the legislative and regulatory environment is an important factor to adopt green computing. In Gulf countries, with the transformation of the energy sector towards renewable energy, many legislations have been enacted to promote environmental sustainability and efficient-energy consumption [16]. In addition, the universities seek to adopt education accreditation standards with the purpose of improving the quality of education, providing better educational services and gaining strategic advantages. These accreditation standards include some criterion of commitment to address energy consumption in ecofriendly manner and engagement in social and environmental responsibility issues. For example, the international criteria and standards for business accreditation (AACSB) involve environmental sustainability criteria that should be implemented in the higher education institutions [35]. Consequently, this legislative and regulatory environment will significantly force universities to adopt green computing projects in their daily practices.

One of the main objectives of the current Gulf governments green policy is determining the best practices to reduce energy 
consumption and carbon emissions, and to avoid e-waste. Therefore, Gulf governments launched several initiatives to encourage all sectors including universities to adopt green projects. For example, currently Gulf governments support and fund the green projects, and award the scientific research ideas that promote an environmental and economic sustainability. Thus, the government policies have a significant impact on universities encouraging to encourage them adopt green computing.

Based on above discussions, the key success factors that affect the adoption of green computing in gulf universities are 8 variables and classified based on the TOE model into three contexts are technology, organizational, and environmental dimensions. The technology context includes IT infrastructure and outsourcing. The organizational context consists of top management support, awareness, relative advantage and adequate resources. Meanwhile, the environmental context comprises the legislative and regulatory environment, and government policy.

\section{METHODOLOGY}

\section{A. Participants and Data Collection}

A survey approach was undertaken to verify the proposed model. The research population of this study is composed of both private and government higher education institutions that already adopted or intend to adopt green computing initiatives in gulf countries. This includes universities and colleges in Saudi, Bahrain, Kuwait, UAE and Oman which amounted around 182 institutions. The research participants of this study are green projects managers and vice presidents for administrative and strategic affairs who are involved in the strategic and operational decisions on the adoption of green computing projects. After e-mail contact, as a result of confidentiality issues or having no attention in adopting green computing initiatives, 19 universities refused to participate in this research. Consequently, only 163 universities and colleges expressed their willingness to participate in this study. Data collection process was begun on 2 July 2017 and was lasting for two months. A 163 questionnaire instruments sent to respondents by e-mail, and after three weeks, an email reminder was sent to participants in order to improve the response rate. A total of 124 responses were obtained, of which 6 were incomplete, and thus rejected. Therefore, the total of valid responses were 118 instruments which represent $72 \%$ of response rate that are deemed suitable for data analysis.

\section{B. Measurements}

The measurements have been identified and adapted based on the current green computing and related IT studies. This study addresses 9 constructs with a total of 32 items. Table I lists these constructs and the associated references, along with the numbers of items for each construct. A 5-point Likert scale was employed for measuring the items, with values ranking between 1 (strongly disagree) and 5 (strongly agree). A higher value reflects a greater level of respondent's agreement with items of questionnaire instrument.
In order to improve the questionnaire instrument validity and minimize the uncertainty and bias in the questions, a pilot study was conducted. The questionnaire was sent to two green computing experts; the first one is academic staff (Associate professor at Princess Nourah bint Abdulrahman University) who has research contribution in green computing topic. The second one is green computing manager project and has more than six years of experience in green computing projects at gulf universities. Some minor corrections were modified based on the comments of experts before distributing the actual survey.

TABLE I. RESEARCH MEASUREMENTS

\begin{tabular}{|l|l|l|l|}
\hline Context & Constructs & Item No. & References \\
\hline \multirow{4}{*}{ Technology } & IT infrastructure & 4 & {$[36,37]$} \\
\cline { 2 - 4 } & Outsourcing & 6 & {$[38,39]$} \\
\hline \multirow{4}{*}{ Organizational } & Top management support & 4 & {$[38,39]$} \\
\cline { 2 - 4 } & Awareness & 4 & {$[15]$} \\
\cline { 2 - 4 } & Relative advantage & 4 & {$[33]$} \\
\cline { 2 - 4 } & Adequate resources & 5 & {$[34]$} \\
\hline \multirow{3}{*}{ Environmental } & $\begin{array}{l}\text { Legislative and regulatory } \\
\text { environment }\end{array}$ & 3 & {$[1,40]$} \\
\cline { 2 - 4 } & Government policy & 2 & {$[41]$} \\
\hline
\end{tabular}

\section{DATA ANALYSIS}

This section addresses the detail descriptive statistics and reliability of items. In this study, the significance of variables is based on frequencies and mean of respondents' view over each point of questionnaire variable using the Statistical Package for the Social Sciences (SPSS) software to validate the success factors affecting the adoption of green computing in gulf universities.

\section{A. Descriptive Statistics}

The data collected from 118 respondents indicate that the higher education institutions in gulf countries comprise four types of institutions are: government universities (29\%), private universities (25\%), government colleges (20\%), and private colleges $(26 \%)$. This distribution is too similar to the real distribution of entire population of higher education institutions in gulf countries. Table II presents the percentage of respondents based on higher education sector in gulf countries. Moreover, data collected shows that 52 university and college $(44 \%)$ have already adopted green computing initiatives, while the rest $(56 \%)$ are intend to adopt green IT projects in their campuses.

\section{B. Reliability Analysis}

As measurements items of constructs adapted and modified from previous related literature, reliability of measurements had to be tested. Therefore, Cronbach's alpha coefficient was used to test reliability and internal consistency of variables items. Statistically, if Cronbach's alpha coefficient scores is more than $0.70(\alpha>0.70)$, the reliability of variable's items is acceptable [42]. In this study, the Cronbach's alpha test indicates that the values for all variables are in the acceptance level $(\alpha>0.70)$. The overall value of Cronbach's alpha is $94.6 \%$ of 32 items from 118 respondents. Table III outlines the Cronbach's alpha score for each variable. 
TABLE II. PERCENTAGE OF RESPONDENTS

\begin{tabular}{|l|l|l|l|l|}
\hline Type & Res. & $\mathbf{\%}$ & Adopt GC & Intend to adopt GC \\
\hline $\begin{array}{l}\text { Government } \\
\text { university }\end{array}$ & 34 & $29 \%$ & 23 & 11 \\
\hline Private university & 29 & $25 \%$ & 14 & 15 \\
\hline Government college & 24 & $20 \%$ & 5 & 19 \\
\hline Private college & 31 & $26 \%$ & 10 & 21 \\
\hline Total & 118 & $100 \%$ & 52 & 66 \\
\hline
\end{tabular}

TABLE III. RELIABILITy CRONBACH'S AlPhA TEST

\begin{tabular}{|l|l|l|}
\hline Variables & N of Items & Cronbach's Alpha \\
\hline IN & 4.00 & 0.798 \\
\hline OS & 6.00 & 0.817 \\
\hline MS & 4.00 & 0.805 \\
\hline AW & 4.00 & 0.874 \\
\hline RA & 4.00 & 0.928 \\
\hline AR & 5.00 & 0.891 \\
\hline LR & 3.00 & 0.784 \\
\hline GP & 2.00 & 0.721 \\
\hline Item-Total & 32.00 & 0.946 \\
\hline
\end{tabular}

\section{FINDINGS AND DISCUSSION}

The findings reveal that the top five factors affect the adoption of green computing in gulf universities are: awareness, relative advantage, top management support, adequate resources and government policy. Table IV shows that the organizational factors is the most important dimension affect the universities' decision to adopt green computing initiatives, followed by environmental dimension, and finally technology dimension. This indicates that the universities must concentrate on the organizational and environmental contexts to support green computing adoption in their campuses. The following subsections present in detail the analysis along with discussions of the empirical findings in respect to the success factors affect the adoption of green computing in gulf universities. The classification of these factors draws on the dimensions of TOE model which are technological, organizational, and environmental contexts.

TABLE IV. FINDINGS ANALYSIS

\begin{tabular}{|l|l|l|l|l|}
\hline Variables & Mean & Std. Deviation & \% & Rank \\
\hline IN & 3.71 & 0.60 & $74.2 \%$ & 8 \\
\hline OS & 3.82 & 0.44 & $76.4 \%$ & 7 \\
\hline MS & 4.20 & 0.30 & $84.0 \%$ & 3 \\
\hline AW & 4.34 & 0.25 & $86.8 \%$ & 1 \\
\hline RA & 4.27 & 0.24 & $85.5 \%$ & 2 \\
\hline AR & 4.18 & 0.27 & $83.6 \%$ & 4 \\
\hline LR & 4.05 & 0.42 & $80.9 \%$ & 6 \\
\hline GP & 4.10 & 0.50 & $82.1 \%$ & 5 \\
\hline Overall & \multicolumn{5}{|l|}{} \\
\hline T & 3.76 & 0.40 & $75.2 \%$ & 3 \\
\hline O & 4.25 & 0.12 & $85.0 \%$ & 1 \\
\hline E & 4.08 & 0.36 & $81.5 \%$ & 2 \\
\hline Valid N & 118 & \multicolumn{2}{|l}{} \\
\hline
\end{tabular}

\section{A. Technology Factors}

The technology factors refer to the internal and external technical aspects involved in green computing adoption. The findings show that $76 \%$ of respondents believed that outsourcing is an important technology factor to adopt green computing. While $74 \%$ of respondents are stated that the IT infrastructure is another success technology factor for green computing adoption in gulf universities (as shown in Table IV). This finding is in line with [8], [18] who stated that the IT infrastructure is one of success factors for green computing projects.

Table IV also illustrates that the technology dimension is the least important factors compared to other organizational and environmental dimensions. This justifies that the respondents think that the adoption of green computing in the context of gulf universities primarily needs to consider organizational and environmental aspects. This result is consistent with [5], [17], [22] who affirmed that the organizational and environmental contexts are most important factors than technology aspects for the adoption of green computing.

\section{B. Organizational Factors}

The findings indicated that the organizational factors are the most important for green computing adoption in gulf universities. Table IV lists these factors which ranked based on the perceptions of respondents, this includes four factors: awareness (Mean 4.34), relative advantage (Mean 4.27), and top management support (Mean 4.20), adequate resources (Mean 4.18). This is due to the vast majority of respondents perceived the adoption of green computing as a huge project involve many benefits for their universities and environment and need a period of time to implement effectively which in turn require improving the awareness among students and staff, resource allocation, support and commitment by top management. Therefore, the organizational factors are truly crucial for adoption of green computing in gulf universities. Numerous studies [13], [14], [28], [31] confirmed that the organizational dimension is among the essential aspects for adopting any new IT initiative including green computing.

\section{Environmental Factors}

Analysis shows that the government policy (Mean 4.10), and legislative and regulatory environment (Mean 4.05) are significant environmental factors affect the universities' decision to adopt green computing in gulf countries. This is because the gulf governments have already implemented legislations and launched green initiatives to promote environmental sustainability and efficient-energy consumption. This serves as outside pressures to encourage universities adopt green computing projects in their work as kind of compliance with environmental commitment. This finding is supported by Du Buisson and Naidoo [5] who stated that the environmental pressures play a vital role to adopt green computing projects.

\section{Comparison Analysis}

The findings revealed that 52 of gulf universities and colleges $(44 \%)$ have already adopted green IT projects in their campuses, while 66 university and college (56\%) are intend to adopt green computing projects in the near future. The findings revealed that 52 of gulf universities and colleges (44\%) have already adopted green IT projects in their campuses, while 66 university and college (56\%) are intend to adopt green computing projects in the near future. Table $\mathrm{V}$ provides comparison between the mean scores of respondents' answers from the universities that already adopted the green computing 
and the universities that intend to adopt green computing projects in the near future.

The mean scores of organizational factors for the universities that adopted (4.38) and the universities intend to adopt green computing (4.11). This indicates that the respondents from both categories are strongly agreed that the organizational factors are an imperative aspect for green computing adoption in gulf universities. This means that internal requirements of green computing adoption are deemed to be the most important drivers than other external pressures or technical aspects. Moreover, the analysis showed that the environmental factors are perceived as more important by universities that intend to adopt green computing (Mean 4.45) than early adopters' universities (Mean 3.70). The reason is that, in past two years, the gulf governments have increasingly implemented legislations and launched several green initiatives to promote environmental sustainability. This indicates the government policy, legislative and regulatory environment are play a significant role to increase the adoption level of green computing projects in gulf universities.

TABLE V. COMPARISON ANALYSIS BETWEEN EARLY ADOPTERS UNIVERSITIES AND INTEND TO ADOPT GREEN COMPUTING

\begin{tabular}{|l|l|l|l|l|}
\hline \multirow{2}{*}{ Variables } & \multicolumn{2}{|l|}{ Early adopters GC } & \multicolumn{2}{l|}{ Intend to adopt GC } \\
\cline { 2 - 5 } & Mean & Std. Deviation & Mean & Std. Deviation \\
\hline IN & 3.84 & 0.60 & 3.58 & 0.60 \\
\hline OS & 3.62 & 0.46 & 4.02 & 0.42 \\
\hline MS & 4.39 & 0.30 & 4.01 & 0.30 \\
\hline AW & 4.41 & 0.23 & 4.26 & 0.25 \\
\hline RA & 4.59 & 0.23 & 3.95 & 0.25 \\
\hline AR & 4.14 & 0.27 & 4.21 & 0.27 \\
\hline LR & 3.68 & 0.42 & 4.42 & 0.42 \\
\hline GP & 3.72 & 0.54 & 4.48 & 0.45 \\
\hline Overall & \multicolumn{5}{|l}{} \\
\hline T & 3.73 & 0.41 & 3.80 & 0.38 \\
\hline O & 4.38 & 0.14 & 4.11 & 0.11 \\
\hline E & 3.70 & 0.37 & 4.45 & 0.35 \\
\hline
\end{tabular}

\section{CONCLUSION}

This study proposes to understand the factors affect the adoption of green computing in gulf universities. This empirical study draws on the TOE model to investigate three contexts affecting universities' decisions regarding the adoption of green computing projects, namely technological, organizational and environmental aspects. The findings revealed that the organizational factors are the most important dimension affecting the adoption of green computing in gulf universities, followed by environmental context, and finally technology dimension. The organizational factors include awareness, relative advantage, management support and having an adequate resource. The environmental context involves government policy, legislative and regulatory environment while the technology dimension comprises outsourcing and IT infrastructure.

The main contribution of this paper is its implications for academia and practitioners. For academia, this study contributes to the theory by employing of TOE model to understand the key areas for the success factors of green computing adoption. The use of TEO model assists in providing taxonomy of the factors affect the adoption of green computing. Yet, there is a lack of studies that classified these factors in current literature. This taxonomy offers further insight on contextual understanding of the key success factors for green computing adoption. Moreover, the findings of this study confirm to the previous studies [5], [17], [22] that the organizational factors are most important aspect than other environmental and technology contexts the adoption of green computing. However, this study contributes to the expansion of the boundaries of knowledge by revealing further insight on the critical role of environmental factors such as government policy in increasing the level of adoption for the universities that intend to adopt green computing. For practitioners, this study highlights the key success factors affecting gulf universities' decision to adopt green computing in their campuses. This will assist the decision makers in gulf countries to benefit from the findings of this study to make well informed decisions by focusing on the key factor that have a greater impact on adopting green computing.

The evidence from this study indicates that the development of government policy towards launching and supporting green initiatives will positively affect the adoption of green computing. Therefore, this study suggests for governments to develop well-defined strategies to encourage universities to adopt green computing. For example, governments may launch green awards or prizes to improve competitive advantage between universities in adopting green computing. Moreover, governments should set the green computing practices in the national academic accreditation criteria to force the universities adopt and implement green computing in their learning processes.

The major limitation of this study is limited to examine the key factors affect the universities' decision to adopt green computing in context of gulf area as developing countries. Understanding the green computing adoption is need different requirements which based on the context of investigation. The situation of Gulf States are somewhat different from other developing countries, as they are relying on oil as a main energy source, and have a huge budgets. Therefore, future studies should use the findings of this study to make comparison with other non-oil developing countries to promote the completeness of this study. Moreover, it would be useful for future research to extend the findings this study by investigating new factors affect the adoption of green computing, particularly in environmental context; for example, the influence of donors and international organization on green computing adoption in developing countries.

\section{REFERENCES}

[1] L. G. Tornatzky and M. Fleischer, Processes of technological innovation. Lexington Books, 1990.

[2] M. A. Mohammed, D. A. Muhammed, and J. M. Abdullahf, "Green Computing Beyond the traditional ways," Int. J. of Multidisciplinary and Current research, vol. 3, 2015.

[3] N. J. Kansal and I. Chana, "Cloud load balancing techniques: A step towards green computing," IJCSI International Journal of Computer Science Issues, vol. 9, no. 1, pp. 238-246, 2012. 
[4] D. Wang, "Meeting green computing challenges," in Electronics Packaging Technology Conference, 2008. EPTC 2008. 10th, 2008, pp. 121-126: IEEE.

[5] W. Du Buisson and R. Naidoo, "Exploring Factors Influencing IT Workers' Green Computing Intention at a South African Firm," in Proceedings of the Southern African Institute for Computer Scientist and Information Technologists Annual Conference 2014 on SAICSIT 2014 Empowered by Technology, 2014, p. 148: ACM.

[6] A. Molla and V. Cooper, "Green IT readiness: A framework and preliminary proof of concept," Australasian journal of information systems, vol. 16, no. 2, 2010.

[7] S. Aggarwal, M. Garg, and P. Kumar, "Green computing is Smart Computing-A Survey," International Journal of Emerging Technology and Advanced Engineering, vol. 2, no. 2, pp. 297-303, 2012.

[8] A. Hooper, "Green computing," Communication of the ACM, vol. 51, no. 10, pp. 11-13, 2008.

[9] B. Bisoyi and B. Das, "An Approach to En Route Environmentally Sustainable Future Through Green Computing," in Smart Computing and Informatics: Springer, 2018, pp. 621-629.

[10] S. Singh, "Green computing strategies \& challenges," in Green Computing and Internet of Things (ICGCIoT), 2015 International Conference on, 2015, pp. 758-760: IEEE.

[11] A. D. Borah, D. Muchahary, S. K. Singh, and J. Borah, "Power Saving Strategies in Green Cloud Computing Systems," International Journal of Grid Distribution Computing, vol. 8, no. 1, pp. 299-306, 2015.

[12] P. Malviya and S. Singh, "A Study about Green Computing," International Journal of Advanced Research in Computer Science and Software Engineering, vol. 3, no. 6, 2013.

[13] R. Sharma, "Approaches for Green Computing," ternational Journal of Innovative Computer Science \& Engineering, vol. 2, no. 3, pp. 52-55, 2015.

[14] K. Usvub, A. M. Farooqi, and M. A. Alam, "Edge Up Green Computing in Cloud Data Centers," International Journal of Advanced Research in Computer Science, vol. 8, no. 2, 2017.

[15] T. B. T. Ahmad, A. Bello, and M. S. Nordin, "Exploring Malaysian university students' awareness of green computing," GSTF Journal on Education (JEd), vol. 1, no. 2, 2014.

[16] Bloomberg, "Saudis Kick Off $\$ 50$ Billion Renewable Energy Plan to Cut Oil Use," ed: Bloomberg, 2017.

[17] N. Xiong, W. Han, and A. Vandenberg, "Green cloud computing schemes based on networks: a survey," Iet Communications, vol. 6, no. 18, pp. 3294-3300, 2012.

[18] S. Murugesan, "Harnessing green IT: Principles and practices," IT professional, vol. 10, no. 1, 2008.

[19] S. Saxena, "Green computing: Need of the hour," Small, vol. 8, no. 2.5, p. 20W, 2015.

[20] P. K. Paul and M. K. Ghose, "Why Green Computing and Green Information Sciences Have Potentialities in Academics and iSchools: Practice and Educational Perspectives," in Advances in Smart Grid and Renewable Energy: Springer, 2018, pp. 103-112.

[21] D. Akaslan and E. L.-C. Law, "E-learning in the Science of Electricity in Higher Education in Turkey in terms of Environment and Energy," in Proceedings of Postgraduate Research Student Conference, 2010.

[22] R. R. McWhorter and J. A. Delello, "Green Computing through Virtual Learning Environments," in Handbook of Research on Innovative Technology Integration in Higher Education: IGI Global, 2015, pp. 1-28.

[23] E. Sultanow, A. Chircu, and F. Chircu, "E-commerce Adoption: A Revelatory Case Study in the German Oncology Pharmaceutical Supply Chain," in Proceedings of the Conference on Information Systems Applied Research ISSN, 2016, vol. 2167, p. 1508.

[24] H. Gangwar, H. Date, and R. Ramaswamy, "Understanding determinants of cloud computing adoption using an integrated TAM-TOE model,"
Journal of Enterprise Information Management, vol. 28, no. 1, pp. 107130, 2015.

[25] P.-F. Hsu, S. Ray, and Y.-Y. Li-Hsieh, "Examining cloud computing adoption intention, pricing mechanism, and deployment model," International Journal of Information Management, vol. 34, no. 4, pp. 474488, 2014.

[26] E. Ansong, S. L. Boateng, R. Boateng, and J. Effah, "Determinants of ELearning Adoption in Universities: Evidence from a Developing Country," in System Sciences (HICSS), 2016 49th Hawaii International Conference on, 2016, pp. 21-30: IEEE.

[27] W. Xu, P. Ou, and W. Fan, "Antecedents of ERP assimilation and its impact on ERP value: A TOE-based model and empirical test," Information Systems Frontiers, vol. 19, no. 1, pp. 13-30, 2017.

[28] H. Sulaiman and A. I. Magaireah, "Factors affecting the adoption of integrated cloudbased e-health record in healthcare organizations: A case study of Jordan," in Information Technology and Multimedia (ICIMU), 2014 International Conference on, 2014, pp. 102-107: IEEE.

[29] Q. Cao, J. Baker, J. C. Wetherbe, and V. C. Gu, "Organizational Adoption of Innovation: Identifying Factors that Influence RFID Adoption in the Healthcare Industry," in ECIS, 2012, vol. 94.

[30] R. U. Khan and S. U. Khan, "Green IT-outsourcing assurance model," in Global Software Engineering Workshops (ICGSEW), 2013 IEEE 8th International Conference on, 2013, pp. 84-87: IEEE.

[31] J.-W. Lian, D. C. Yen, and Y.-T. Wang, "An exploratory study to understand the critical factors affecting the decision to adopt cloud computing in Taiwan hospital," International Journal of Information Management, vol. 34, no. 1, pp. 28-36, 2014.

[32] L. G. Tornatzky and K. J. Klein, "Innovation characteristics and innovation adoption-implementation: A meta-analysis of findings," IEEE Transactions on engineering management, no. 1, pp. 28-45, 1982.

[33] G. Premkumar and M. Roberts, "Adoption of new information technologies in rural small businesses," Omega, vol. 27, no. 4, pp. 467484, 1999.

[34] I.-C. Chang, H.-G. Hwang, M.-C. Hung, M.-H. Lin, and D. C. Yen, "Factors affecting the adoption of electronic signature: Executives' perspective of hospital information department," Decision Support Systems, vol. 44, no. 1, pp. 350-359, 2007.

[35] AACSB, "Eligibility Procedures and Accreditation Standards for Business Accreditation," 2013.

[36] G. Premkumar and K. Ramamurthy, "The role of interorganizational and organizational factors on the decision mode for adoption of interorganizational systems," Decision sciences, vol. 26, no. 3, pp. 303336, 1995.

[37] D. E. T. Terry Anthony Byrd, "Measuring the flexibility of information technology infrastructure: Exploratory analysis of a construct," Journal of Management Information Systems, vol. 17, no. 1, pp. 167-208, 2000.

[38] V. Grover, M. J. Cheon, and J. T. Teng, "The effect of service quality and partnership on the outsourcing of information systems functions," Journal of Management Information Systems, vol. 12, no. 4, pp. 89-116, 1996.

[39] J. Rhodes, P. Lok, W. Loh, and V. Cheng, "Critical success factors in relationship management for services outsourcing," Service Business, vol. 10, no. 1, pp. 59-86, 2016.

[40] A. P. Chan, P. T. Lam, D. W. Chan, E. Cheung, and Y. Ke, "Critical success factors for PPPs in infrastructure developments: Chinese perspective," Journal of Construction Engineering and Management, vol. 136, no. 5, pp. 484-494, 2010.

[41] K. K. Kuan and P. Y. Chau, "A perception-based model for EDI adoption in small businesses using a technology-organization-environment framework," Information \& management, vol. 38, no. 8, pp. 507-521, 2001.

[42] J. F. Hair, W. C. Black, B. J. Babin, R. E. Anderson, and R. L. Tatham, Multivariate data analysis. . Pearson, 2010. 